\title{
An Integrative Multi-Dimensional Model of Culturally Relevant Academic Evaluation for the 21st Century
}

\author{
Idit Finkelstein $^{1}$, Shira Soffer-Vital ${ }^{1}$, Yael Shraga-Roitman ${ }^{1}$, \\ Revital Cohen-Liverant ${ }^{1} \&$ Tsfira Grebelsky-Lichtman ${ }^{1,2}$
}

\author{
${ }^{1}$ Ono Academic College, Israel \\ ${ }^{2}$ The Hebrew University, Israel \\ Correspondence: Idit Finkelstein, Associate Dean, The Faculty of Social Sciences, Ono Academic College, Israel.
}

Received: July 1, 2021

Accepted: September 14, 2021

Online Published: September 16, 2021

doi:10.5430/ijhe.v11n1p187

URL: https://doi.org/10.5430/ijhe.v11n1p187

\begin{abstract}
Due to Covid-19, the world has encountered new challenges regarding pedagogy, learning, assessment, and evaluation. In meeting these challenges, there have been rapid changes in learning, and the gap between pedagogy and evaluation has grown. The purpose of this paper is to develop a new evaluative model suitable for the technologically enhanced, multicultural environment of the $21^{\text {st }}$ century. In this article, we develop a unique multidimensional model of Culturally Relevant Academic Evaluation (CRAE) that fills a gap in the scientific literature on evaluation in higher education. The model depicts evaluation as an integrated process of four dimensions: two of them based on the well-established dimensions of learning and curriculum, and two based on the novel dimensions of inclusive multiculturalism and technology. We consider evaluation in its broad context in higher education, and we analyze the interrelations between the four dimensions of the evaluation process, discussing their contribution to the enhancement of evaluation in higher education.
\end{abstract}

Keywords: evaluation, higher education, multiculturalism, technology, Covid-19

\section{Introduction}

In the multicultural, global reality, where technological changes are rapid and modern life is flooded with information, there is a growing need to adjust educational perceptions and evaluation processes. With the Covid-19 pandemic, this need has been amplified: we need to modify evaluation processes in academia to fit technological platforms, creating the opportunity to promote diverse and meaningful online evaluations. The pandemic has highlighted the importance of the argument of Marginson and Considine (2000) concerning the willingness of academic institutions to reinvent themselves. Evaluation is crucial before reinvention can take place, and we thus saw a need for a new model of creative evaluation in higher education.

Today's students are supplied with fast, available, and easily accessible information, and our ability to consume information is constantly improving. Alongside technological changes, multicultural complexity has also caught the attention of researchers worldwide. Nonetheless, there is a research gap in the area of academic evaluation adapted to technology in general, and within a multicultural environment in particular.

Is academia able to keep up with the fast-paced changes? Is academia able to adjust its evaluation methods to a learning environment that is multicultural, diverse, and adapted to these fast-paced technological changes? These questions are aligned with Case's (2013) novel notions regarding students' learning in higher education, such as: What changes in student agency might be considered desirable outcomes for higher education? And how will the system need to change (structurally and culturally) to better enable these desired changes in student agency?

Cantwell's (2019) ideas about student mobility have wide implications, especially in the era of the Covid-19 pandemic. International students no longer have the regular constraints of time and place for their higher education, and our model can provide academic institutions with a practical tool for inclusive multicultural evaluation.

Evaluation represents a core part of learning in higher education, as stated by Bransford, Brown and Cocking (2000), since evaluation is a key component of effective learning. The main objective of this theoretical article is to present a multidimensional model for conducting meaningful evaluation in the academy that is suited to multiculturally diverse groups and to technological progress. 


\section{Theoretical Framework}

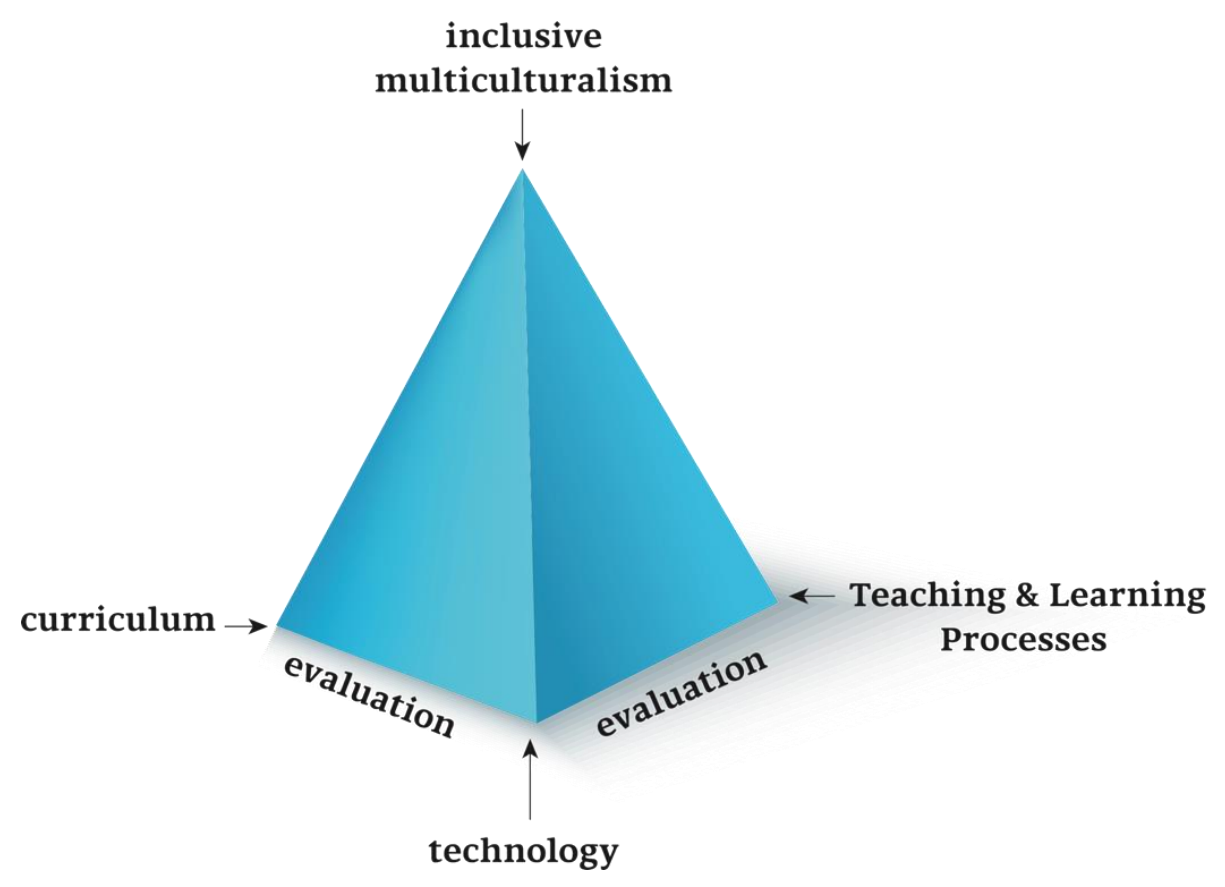

\subsection{The Basis of the Model: Evaluation}

Evaluating and measuring student achievement is a key aspect of academia. Yet evaluation itself is scarcely reappraised, and it is rarely studied in aspects unrelated to pedagogy and the curriculum. Academic evaluation is perceived as feedback on the quality of students' performance and carries with it the value of reward (Sanders et al., 1997). Evaluation is an ongoing activity, in which lecturers systematically collect information about students' work. Students have many different perceptions of evaluation, its various types, its function, and its efficacy (Levy, 2003).

Exams and grades are sometimes a source of concern and anxiety for students. For many of them, the grade is the "bottom line" of the course and therefore it is one of the strongest motivational factors for learning (Khalaila, 2015). Students feel frustrated in the following situations: when examinations do not include all the material they were meant to include; when students are not given enough time to think about the examination questions; when the level of the examination questions is much higher than the level of the material taught in class; when students are not given enough information before the examination about how it will be composed and graded (Legult et al., 2006). Evaluation may also lead to frustration when the reasons for failing or succeeding are not explained or understood (Butler \& Orion, 1990).

Examinations and papers, the leading means of evaluation in academia, may serve as auxiliary tools in navigating students' learning, provided the lecturer uses them appropriately (Legult et al., 2006). On the other hand, if the lecturer does not know how to use them properly, the examinations may become a liability for the students and cause them to become tired of learning. Traditional evaluation places examinations center stage, where the examination is an isolated event used to measure the individual's achievements and to make decisions about the learner (Nevo, 1998). Thus, in traditional evaluation, student achievement is largely expressed in the grade of the final examination. Sometimes, the value of the grades in the eyes of the students stems largely from their fear of damage to their self-image and from losing the approval and support of the significant people in their lives (Nevo, 1998).

The evaluation types common today are traditional and alternative assessments that can be either summative or formative. With the growing awareness of putting the learners and their educational needs first, and with the growing importance attributed to strengthening the graduate's independent character, the need arose to adjust the type of evaluation and diversify evaluation methods. The advantage of formative evaluation is that it provides the learners with a reliable reflection of their achievements over time and a processive understanding of their academic progress. Beyond the monitoring capacity that a formative evaluation provides regarding students' achievements, it also helps them develop effective learning strategies to nurture their learner independence. 
Nowadays, the use of alternative assessment is becoming more and more common in schools, but in academia it still seems to be quite negligible. The common academic mindset is still based on traditional evaluation. Alternative evaluation is based on gathering data for integrative interpretation of the students' achievements through complex, challenging, interesting assignments requiring performance that shows understanding. This kind of evaluation highlights each learner's uniqueness, as well as the variance among students (Birenbaum, 1997). Such evaluation is also needed in the academy--evaluation that can highlight the uniqueness of each student, in keeping with their gender and cultural background. Academic education professionals must do their best to create a meaningful, equitable, and unbiased evaluation that reflects student variance and diversity, in which the learning products are synchronized with each student's world and culture.

\subsection{Expanding the Basic Model: From Curriculum, Pedagogy and Evaluation, to Teaching-Learning Processes, Curriculum, and Evaluation}

The basic model was mainly developed in the context of schools; however, in our research, we view pedagogy in a broader context of Teaching-Learning Processes (TLP). Evaluation is not an isolated, stand-alone component within the educational setting. The content measured and how it is expressed largely depends on the curriculum and the pedagogy. Evaluation is not only affected by these components, it also affects and dictates them. These components should be coordinated with one another and should both seek to achieve the same goals and strengthen each other. If this is not the case, the components proceed simultaneously and separately from one another. This situation may disrupt and damage the educational process, and then the evaluation products would not accurately reflect the teaching-learning goals; or alternatively, teaching would be ineffective (Pellegrino, Chudowsky, \& Glaser, 2001).

However, it is difficult to achieve unity between Teaching-Learning Processes, curriculum, and evaluation, since these are often defined by different people. For instance, the curriculum may be set by the Department Head, the evaluation method may be determined by the course or program coordinator, and the teaching-learning methods may be defined by the lecturer. Each of these educators has different needs and uses the evaluation for different purposes. Some of the components are built top-down while others are built bottom-up. Therefore, the coordination should be done not only at the same level (class, department and faculty level) but also between the various levels. They all have to be coordinated with the evaluation triangle of cognition, observation and interpretation. If these conditions are not met, the evaluation will not be meaningful (Pellegrino, Chudowsky, \& Glaser, 2001).

First, we elaborated this basic model (curriculum, pedagogy and evaluation), and then we expanded this model to a more comprehensive and holistic model, which takes into account the Teaching-Learning Processes (TLP), curriculum, and evaluation as a more suitable framework for higher education settings.

The triangle of evaluation, pedagogy, and curriculum was developed on the basis of theories of learning and how it can take place in various disciplines (Bransford, Brown, \& Cocking, 2000). As a rule, the goal of the educational process is to develop higher-order thinking skills, such as deductive reasoning, critical thinking, and problem-solving abilities, and these will not be independently developed unless they are built into the curriculum (Achtenhagen, 2012).

Defining the goals of the educational process is essential for establishing a curriculum with continuity and cohesion between its various components. Therefore, the development of an educational curriculum must be based, first and foremost, on setting uniform standards for defining the teaching goals, contents, and methods of evaluation. These standards, whose function is to serve as evaluation markers and help with the setting of goals, sometimes become the teaching goals themselves, and thus drive educational practices. A curriculum in which the uniform standards are identical to the teaching goals may become "an exclusionary curriculum" - one that denies access to learners from population groups outside the mainstream (Sleeter \& Carmona, 2017).

The essentials of the scientific discourse about a multicultural curriculum mainly deal with the content that should be learned in the various educational frameworks, focusing on the content included in it versus those that are excluded (Sleeter, 2016). According to Banks and Banks (2020), a multicultural curriculum means dealing with content that is taught for the most part outside mainstream education and providing extensive reference to cultural and social diversity. The difference in multicultural curricular content testifies not only to the content itself, but also to the starting point from which it develops, based on a two-way discourse between education professionals and the community about values and ideas (Sleeter \& Carmona, 2017). A curriculum constructed in this manner encourages the learners to become an integral part of the learning process, to legitimize their own voice and personal opinions, and to directly affect the content studied (Banks \& Banks, 2019). 
However, the curriculum alone, however multicultural, is only part of the whole educational process reflected in both teaching-learning practices and evaluation. Observing the content of learning in isolation from teaching and evaluation may create only a partial match to the multicultural mindset and lead to a fragmented learning experience full of internal contradictions. For example, a curriculum in art studies that deals with folklore and the way it corresponds with contemporary events would be more complete if students researched their positions from the existing folklore in the culture to which they belong (Nieto, 2015).

Although there are many views on how to define pedagogy, in its narrow definition pedagogy is the instructional practice applied in education, and its role is to be a social agent (Torres, 1996), connecting academic content (didactics) and how it is delivered to the learners (methodology) (Alexander, 2004, 2018). The materials presented and demonstrated to the learners are often taken from the dominant culture, and the use of materials from cultures outside the mainstream is less common (Alemán, 2014). Moreover, the use of various teaching techniques may be accessible in different ways to different populations (Paris \& Alm, 2014).

\subsection{The Relationship Between Evaluation, Pedagogy, and Curriculum in the Basic Model}

As an academic faculty, we see that evaluation is often detached from the teaching, pedagogical methods, and curriculum as reflected in the course syllabus. This detachment, both conceptually and in terms of timing when it comes to a summative evaluation, has far-reaching implications for the learning process. When we look for a rationale for choosing one evaluation tool over another alongside the choice of the content we seek to evaluate and the curriculum and pedagogical methods, we can scarcely find one. But the absence of such a conceptual connection has implications for the learners' level of functioning, understanding, and performance.

The relationship between evaluation, pedagogy, and curricula has been discussed by researchers for many years (Fuchs, 1984), and in recent years also in its technological context (e.g., Vrasidas et al., 2000). Evaluation affects pedagogical processes; when the pedagogical approach assumes that learners are involved in their learning process, then the evaluation process should also seek to include and involve them (Luxton-Reilly, 2009).

Many studies have shown the advantages of thinking ahead about the compatibility between the pedagogical process and the evaluation (Taylor \& Evans, 2005). In project-based learning (PBL) and case-study analysis, coordinating between pedagogy and evaluation promotes thinking and understanding among the students (McWhirter \& Shealy, 2018). Planning pedagogical strategies in line with a compatible evaluation is also important for promoting students' critical thinking skills (McWhirter \& Shealy, 2018).

In a study that sought to examine how to promote students' understanding by aligning pedagogy with evaluation, the students participated in a course on research methods, planned an interview, and randomly interviewed several other students. Based on their experience, they wrote a paper addressing methodological issues. The instructor chose the topic, trained the students how to interview, entered the data, and formed tables to examine the students' conjectures. By directly participating in significant research, the students deepened their understanding of research methods and understood the many aspects involved in conducting a study (Royce, 2007).

Moreover, some studies indicate that pre-coordinating curriculum, pedagogy, and evaluation is critical for the success of struggling students (Heid, 1995; Kelley et. al., 2008). This combination was also found to have a positive effect on people with disabilities (Stecker et al., 2005). Many students formulate an insight into the course's "hidden curriculum" based on this information (Birenbaum \& Dochy, 2012).

This dictates their attitude towards studying in the course. Experience and research show that a large number of students are dissatisfied with the quality of evaluation. Their arguments relate mainly to the incompatibility between the exam questions and the content, and the type of questions to which they were exposed during the course, as well as to the length of time allotted for the examination. Among education professionals, it is widely accepted that the compatibility between teaching, learning, and evaluation is essential to achieving educational goals in all educational frameworks. Higher education goals have changed over recent years in order to adjust education to the skills required for learners' successful functioning in the knowledge era. It is now commonly accepted that students who study in a higher education institution will have to keep renewing their professional knowledge throughout their lives (Birenbaum \& Dochy, 2012; Bar Shalom, Grebelsky-Lichtman, \& Alayan, 2018).

To summarize: the basic model refers to pedagogy, curriculum, and evaluation. While the terms "curriculum" and "evaluation" are highly relevant and suitable to higher education, we claim that the term "pedagogy" might be too narrow for our goals to adapt the basic model for higher education. In the basic model the term "pedagogy" is used. However, in higher education, we find that the term "TLP" is more suitable for describing and analyzing the educational processes. Pedagogy is a common reference in academic settings, especially in schools. However, in 
higher education, we have to widen our perspective. In this article we expand the basic model to a more comprehensive one, using the term "TLP," which will be explained below.

\section{Towards A New Model: Teaching-Learning Processes (TLP) in a Multicultural Context}

We found the term "TLP" to be more theoretically suitable than the term "pedagogy," especially for multicultural settings. The roots of multicultural observation of TLP lie in critical pedagogy, according to which teaching processes can create social change and promote social justice (Nieto, 2010). In his seminal book "Pedagogy of the Oppressed" (1970), the educational philosopher Freire referred to the education system as one that maintained the balance of power between two social groups - oppressors and oppressed. He claimed that educational practice can challenge its traditional role and seek to free learners from the social role they were assigned (Freire, 2018). This could be achieved through authentic dialogue, a commitment to action, imparting knowledge and developing creativity, and through constant reflection (Macedo, 2018).

At the practical level, multicultural pedagogy has evolved not only from an overall perception of the role of educators, but also from a practical understanding that the learning process becomes meaningful for learners when the acquired knowledge is relevant for them (Saint-Hilaire, 2014). A learning process that includes a multicultural reference improves the learning experience by allowing the learners a higher degree of involvement (De La Mare, 2014). Furthermore, it empowers the learners by allowing them to recognize their personal voice, formulate their self-identity, and strengthen their sense of self-worth (Saint-Hilaire, 2014).

The research literature on multicultural pedagogy presents the evaluation process as secondary, of lower priority in relation to the learning process that takes place in the classroom (Ford, 2014; Ghosh \& Galczynski, 2014). However, the evaluation process is of great importance and it largely defines the learning process (Black \&Wiliam, 2018), especially in higher education institutions, where great emphasis is placed on achievement measured on the basis of grades (Schneider \& Preckel, 2017). Therefore, we find the term TLP as more suitable for higher education, which has unique characteristics that are different from school characteristics, such as: multiculturalism, independent learning, preparing the student for the future, and a changing labor market.

\section{Inclusive Multicultural Evaluation}

Inclusion in academia is as theoretical as it is practical. In order to discuss evaluation for a wide range of higher education learners, it is important to first understand the meaning of evaluation for learners belonging to minority groups, among whom, in Israel, are those whose mother tongue is not Hebrew and those who are learners with disabilities. This group may also include learners who are first-generation in higher education, who constitute a minority group among people turning to higher education (Hendin, 2014). Evaluation processes at school are remembered by some of them as fraught with difficulties and failures, and by some as detached from the accepted method of evaluation in academia (Liasidou, 2014). Although they recognize the importance of the evaluation process in their studies, their previous experiences do not provide them with a solid foundation that can help them make the most of their evaluation.

These learners find it difficult to express their abilities in the evaluation tools currently accepted in academia for two main reasons. First, verbal, mathematical, and technological literacy, as well as learning skills, are perceived as early knowledge that learners must bring to academia as they greatly influence the results of any evaluation. Secondly, currently accepted evaluation tools do not adequately reflect the contribution of the learning process to the learners themselves and the personal learning curve of each learner.

\subsection{Literacy and Learning Skills as a Built-in Part of the Evaluation}

Most accepted methods of evaluation in higher education require a high level of verbal, mathematical, and technological literacy, in accordance with the students' chosen field of study. In Israel, students are required to have a high level of verbal ability in Hebrew and English with a broad vocabulary, an understanding of what they read and hear, as well as competent writing ability. Learners in disciplines that include mathematics courses are required to have good mathematical understanding and the ability to use mathematical language for problem solving. They must also be able to work in a computerized environment and to quickly learn applications and software. In addition, learners are required to express their learning skills by being examined and by writing exercises and assignments; for example, they need to demonstrate their ability to locate materials, summarize and organize information, as well as formulate and justify new arguments. All these, although they are a key component for evaluation, are not reflected within the learning process and are only generally reflected within the lecturers' stated demands. Learners who belong to minority groups face knowledge gaps in these areas and, in addition to focusing on the course content, are required to overcome the additional gaps that exist between them and their classmates. 


\subsection{Evaluation as the Reflection of a Personal Learning Process}

For learners who belong to minority groups, in addition to being evaluated vis-à-vis their peer group, there is great significance for the personal learning process they undergo throughout their studies. These learners are required to invest multiple resources in order to overcome the gaps mentioned above. The level of investment is not always reflected in the final product when compared to the peer group, but it can testify to their own personal progress compared to their previous achievements. For learners from minority groups, a high learning curve can testify to metacognitive capabilities, including the ability to monitor products and processes, and high self-awareness. These capabilities are not reflected in the evaluation process, despite their great contribution to the learners' success in their continued studies and in the job market.

\subsection{UDL - Universal Design for Learning}

The main frame of reference formulated for the purpose of teaching a wide range of learners is the UDL (universal design for learning). This design was developed as part of the trend of integrating and including children with disabilities in mainstream settings and was expanded into higher education (Rose et al., 2006). This frame of reference highlighted the importance of flexibility in three core areas of the curriculum, pedagogy, and evaluation alike: setting learning goals, selecting teaching materials and methods, and developing ongoing evaluation processes (Bernacchio \& Mullen, 2007). According to the UDL, the starting point of teaching-learning is to plan the curriculum according to the students' needs, desires, and abilities. This way the learning process takes all learners into account and proactively works in favor of their success (Capp, 2017). This frame of reference seeks to delve into the learning process and encourages students to be proactive learners who can navigate through their learning process by giving them choices, setting personal goals, and developing awareness of their personal learning skills. The UDL presents three major components that form part of a full, meaningful learning process, and it also offers various ways to apply diversity to each of these components (Cast, 2018).

The first component is engagement. This relates to the emotional aspect of learning and stresses the need to promote learners' involvement in heterogeneous classrooms with a wide range of learners, each of whom has a unique way to become more involved in class. For example, linking the learning material can be relevant to one learner but irrelevant to another (Dean, Lee-Post, \& Hapke, 2017). This component also relates to aspects of emotional regulation in the learning process, and it acknowledges the fact that some learners may perceive a certain form of learning as threatening, while others might perceive it as interesting and challenging (Griful-Freixenet et al., 2017).

The second component is representation. This relates to the sensory aspect of learning, emphasizing the need to make the material accessible to different learners by diversifying its presentation (Cast, 2018). It relates to the various preferences through which the study material is absorbed and understood by the learners; and it stresses the importance of presenting the information in various modes of input (watching, listening, reading, etc.), organizing the information in a clearly comprehensible manner (flowcharts, highlighting important information, etc.), and adding tools that support understanding of the material (a course glossary, concept cards, etc.) (Black, Weinberg, \& Brodwin, 2015).

The third component is action and expression. This relates to the diverse modes of expression that are enabled (Cast, 2018). It addresses the various activities taking place in the classroom that allow personal expression, such as group work and class discussions, as well as the products the learners are required to present (e.g., a written assignment, a practical project, or a presentation). It also deals with technological tools that enable various modes of expression and with how learning-supportive technologies can enable learners with disabilities to express themselves (Evmenova, 2018). Another aspect of action and expression includes the need for the education professional's treatment in breaking down the learning process into stages, providing students with self-supervision tools, feedback at different stages of learning, recommendations for effective learning strategies, and referring them to instructors/guides who can help them use technology and improve their learning skills (Thomas, Van Garderen, Scheuermann, \& Lee, 2015).

\subsection{A Multidimensional Model for Diversified, Multicultural Evaluation}

In the traditional academic mindset, the differences among students were considered an obstacle to educational equality (Ladson-Billings, 2006; Au, 2010). Subsequently, education reforms sought to bring all students to the same level of educational achievements through standardizing the curriculum, regardless of background, race, and status (Patton, 2011). However, studies have shown that such reforms had very little impact on minimizing gaps in student achievement (Bjorklund-Young \& Stratte Plasman, 2020). 
In the research literature, some scholars attribute the standstill in the achievement gaps among students from different cultures to the worldview expressed in the deficit model (Hambacher \& Thompson, 2015). This model is based on a worldview that people from cultural minority groups are unable to attain the same achievements as people from the dominant culture, largely due to their cultural background. People from minority groups are different because their culture is flawed in many ways compared to the dominant culture. Achievement gaps are largely due to the fact that the culture of minority groups is dysfunctional and lacks important characteristics compared to the dominant culture. This worldview led policy makers to demand that education institutions raise the achievements of all their students, regardless of social or ethnic background. However, this policy has not proven successful in practice (Au, 2009; Bjorklund-Young \& Stratte Plasman, 2020).

The modern approach promotes an opposite policy, favoring culturally responsive pedagogy (CRP), which raises the cultural difference as a source of academic excellence. In other words, unlike the traditional inclination to focus on students' weaknesses deriving from their cultural backgrounds, the new approach seeks to consider cultural difference as a source of students' strengths (Gay, 2000; Ladson-Billings, 1995; Vavrus, 2008).

Instead of continuing with standardization, education professionals should acknowledge that the history of racial or socioeconomic exclusion continues to shape the curricula and evaluation tools of our time, and this has to change. Standard evaluation tools ignore the cultural reality and the socio-historical contexts that critically affect students' performance.

National reforms that seek to eliminate the differences among students will never close the achievement gaps between students from different cultures. Instead, we must move toward the implementation of culturally responsive pedagogical practices in professional development and the construction of curricula and evaluation tools derived from this multicultural worldview.

\section{Evaluation and Technology}

At the present time, which is characterized by technology-based learning due to the Covid-19 crisis, we academic education professionals must rethink pedagogy, teaching, and evaluation. While teaching methods show relatively broad diversity, with most efforts being directed at coordinating the teaching methods to the available technological tools, and with online learning and blended learning establishing themselves in $21^{\text {st }}$-century academia, the tools and methods of evaluation have largely remained unchanged.

Moreover, the digital era, characterized by information flooding, requires changes in teaching and evaluation methods, turning them into educational activities in information-rich environments and raising the need to experience these environments and technologies. The Covid-19 period has removed the barriers to promoting this kind of learning.

Digital evaluation tools can be good news for lecturers. This is because they allow analysis of extensive information about the students' activities and provide students with immediate feedback and formative assessment, and at the same time, the lecturers learn how each student is doing during class, which allows them to personally coordinate the contents and pace at each point. Technology-based learning shows how information and communication technologies are applied to learning and teaching. However, there is insufficient evidence that a common understanding has developed in higher education of what constitutes the enhancement or cultivation of the learning experience (Kirkwood \& Price, 2014).

These changes in the perception of teaching and learning increase the need for alternative evaluation that would be appropriate for the environment in which learners are active and responsible for their learning. The present paper presents a model that combines the technological and multicultural aspects of the evaluation process, alongside approaches toward evaluation in diverse learning environments, including ones that integrate technology, while examining learning, interpersonal, effective and reflective processes, and design characteristics. We present a selection of methods and tools that may serve the evaluation tasks in these environments, and we include measurements to evaluate reflection and interaction with the environment partners.

The current era of accelerated change due to Covid-19 has placed the issue of learning in a technological environment, with all its implications, on the public and academic agenda. The need for experiential learning and evaluation activities that incorporate work in e-learning environments is more significant today than ever. This era requires a more meaningful examination of online and remote teaching with reference to a variety of new models of online teaching and assessment, an integration of collaborative learning, and forums that encourage original thinking and enable quality discussion comparable with what is possible in the classroom. Hence the need to reconcile methods of evaluation with the various modes of teaching now employed. 
Integrating technology-based learning must be future-oriented but not futuristic. It should be designed according to the space and practices of design that will not seem dated a few years from now. Therefore it cannot be confined to the tools and assumptions of the present moment. There should be a path and pace of change, but we should not be caught up in wishful thinking or in romanticizing technology. Education should be based on the wisdom of design in order to promote results for most students. Technological design is not performed at the individual level but requires a team of experts.

While in schools alternative evaluation is applied and perfected all the time, in academia in Israel use of this type of alternative evaluation is still scarce. Usually the exam score at the end of the semester is a key, if not exclusive, component in determining the course grade (Birenbaum \& Dochy, 2012).

Technology can support evaluation in various ways, such as evaluating the students' learning process at various points during a course. The use of educational technology can also be diversified in formative assessment, help strengthen engagement, identify knowledge gaps, and support deeper learning. Examples of improving learning and evaluation processes can be increasing flexibility in learning, allowing students an adjusted technological solution (in a cloud, in a collaborative file, etc.) that will allow them flexibility in adjusting evaluation times according to their needs and learning style. All the students need for this is available internet and an adapted virtual environment. Adapted learning has been found to raise motivation (Ennouamani, Mahani, \& Akharraz, 2020).

Cloud-learning solutions such as ClassFlow enable lecturers to evaluate students' achievements and their level of understanding of the learned material during the learning process itself. The immediate feedback helps lecturers adjust the teaching in lectures to the students' progress and to any gaps discovered. Personally adjusted evaluation can also provide the students with feedback and improve their learning process in real-time.

When we shape technology-based learning we must also relate to culture, in addition to the psychological, pedagogical, and pragmatic aspects. The cultural assumptions about education are an important aspect that we must take into account when we build technology-based learning environments. One can apply the claim of Chen and colleagues (1999) also in the context of evaluation and argue that evaluation must be based on the cultural context in which it is applied.

Online learning requires formative assessment in order to allow students to monitor their own achievements. Vonderwell, Liang, and Alderman (2007) related to online learning, stating that evaluation is very significant in online learning because of its characteristics of interactivity and the use of technological tools. For example, peer evaluation promotes meaningful interaction, combined with an effective learning community, which are components of collaboration and interaction significant for promoting a socio-cognitive process alongside critical thinking (Kehrwald, 2010).

Since future-oriented learning environments will involve online digital platforms, in order to prepare graduates for the future job market and ensure their ability to apply what they have learned, we must prepare them for meaningful evaluation processes relevant to their world, where they will express themselves as independent learners who take responsibility for their learning. Future-oriented learning environments that enable technology-based evaluation open up many options for education professionals in academia, including the provision of immediate feedback for implementation, which will promote formative assessment.

\section{Examples of the Model's Applications}

\subsection{First Example: PBL (Project Based Learning) Evaluation of Several Courses - General Mindset}

Today there is growing awareness of integrating alternative evaluation tools. Yet we see that evaluation in academia is conservative and almost unchanged. It usually involves papers and exams. We believe that the very choice of an evaluation tool makes a statement, and has meaning for both lecturers and students. When lecturers choose to test their students through a multiple-choice exam or through a PBL, this choice reflects their view of the course contents and characteristics and of how the students should be tested in order to "measure" their knowledge.

In a comparative examination of different academic institutions, we learned that few institutions included alternative assessment methods. Moreover, the exam or paper is usually perceived as an event that takes place at the end of the course and not as its high point. They are perceived as achievement-measuring tools--not as part of the curriculum or the pedagogical methods used during the course. Many evaluation tools are at the academic lecturers' disposal, which allow them not only to evaluate the students' achievements, but also to use the evaluation and its various tools to benefit the students' learning process. Changing the way lecturers think about evaluation in general and expanding the range of options for using evaluation tools are the order of the day. The Covid-19 period, having challenged the traditional teaching methods, has opened many new, diversified options for us, which are now more relevant than 
ever. If, until now, lecturers were satisfied with an exam or a summative paper, the pedagogical change that has taken place requires that we reconsider evaluation and the evaluation methods we use. According to the basic model, evaluation tools should be aligned with the curriculum and pedagogy. In other words, at the ideal level, lecturers are supposed to choose the evaluation tools in a way that would be conceptually connected to the course syllabus as well as to the teaching methods used. According to the model proposed in this article, adjusting the evaluation tools should suit both the multicultural aspect and the technological aspect. From the multicultural aspect, the evaluation tool should suit and faithfully reflect the different cultures the students come from--their cultural uniqueness. The lecturers' cultural capability should be reflected in the evaluation methods they choose for their students. Technologically speaking, the evaluation should reflect the students' technological literacy, which is required now more than ever.

If so, how can this be carried out? It can be done by connecting courses independently. This is because courses do not often "interact." A certain phenomenon may have been studied in one course in a particular context, and then in another course in a different context, but the lecturers themselves did not make any connections between the courses' contents. Therefore, PBL and its evaluation can allow us to embark with the students on a learning and evaluation journey based on project development in a way that would combine several courses together. First and foremost, this process requires that lecturers from different courses confer and understand the similarities in their courses' content. These projects should connect to the students' inner worlds, their interest areas, culture, and language.

\subsubsection{Project-Based Learning Principles}

The central principle of this approach is that "the whole is greater than the sum of its parts." Project-based work allows deep and holistic observation of a phenomenon, topic, or issue, while adopting a different perspective through which to observe it.

\subsubsection{An Example from the Field}

The issue of gender inequality can be relevant for other courses as well; it can be studied through the prism of legal issues in education, as well as in its economic, philosophical, and psychological aspects. A summative assessment task for several courses can be based on a comprehensive, in-depth, and critical analysis of a certain phenomenon from several content areas.

\subsubsection{Type of Evaluation}

The evaluation in PBL is formative in nature--it is the process that counts. The students learn to think, revise, and then think and revise again. The students learn to shape their own learning and thinking processes and to develop critical, in-depth, comprehensive thinking.

\subsection{A Second Example of the Model's Application: The Planning and Execution of A Zoom Debate and Reflection on It}

One of the options available to lecturers in order to incorporate the dimensions we have dealt with in this article into the evaluation process is the planning of a debate by course participants, its execution, and the subsequent critical analysis of it. In this process the students are active partners in their evaluation process. This example reflects all the model's dimensions: multiculturalism, curriculum, and technology. These dimensions are intertwined and constitute the basis of the formative and summative evaluation process with the students. We shall expand on each dimension below and finally address the evaluation process that is the basis and anchor for all these dimensions.

\subsubsection{The Multicultural Dimension}

This dimension refers to how the voices of students from different cultures are not only heard and represented in the evaluation process but form a significant part of the learning and teaching process. The attitudes of students who are affected by the culture they come from, and their interpretation of concepts, theories, models, and all the content learned in the course, carry great significance in its learning and evaluation processes. In the example presented here, the students are required to plan a debate about a particular topic in the course that is relevant, interesting, and stimulating on the one hand, and open to complicated analysis, with the potential of presenting diverse attitudes, on the other. This reflects the multicultural dimension, where each student presents his/her attitude towards the topic, based on what was learned in the course, but at the same time projects an attitude that stems from his/her culture, previous experience, and inner world. A debate is an opportunity for all the participants to be exposed to different cultures and different attitudes in a way that may enrich their cultural world. This cultural wealth that is brought up in the debate contributes to the students by expanding their understanding of the learned material. This cultural wealth also allows the students to become acquainted with the range of possible interpretations for the studied 
material and to study it from a variety of perspectives. It also makes a significant contribution to the students' professional development and deepens their systemic understanding.

\subsubsection{The Curriculum Dimension}

The curriculum is supposed to be reflected in the course evaluation process. The studied materials are supposed to be faithfully represented in the evaluation and its tools. Optimally, the students are active partners in figuring out the inner connections between the concepts, theories, and models examined, and they are also partners in selecting the significant course materials to be included in the evaluation. In the example below, the curriculum dimension is reflected in the choice of topic for the class debate. This choice is in itself a task that requires in-depth, systematic, and critical study and observation of the course curriculum. The students are required to think what topics and issues have elements that could be disputed and are suitable for a class debate. The planning of the debate and the questions to be raised require students to constantly examine the alignment with the curriculum holistically and laterally in a way that may encourage connections between different concepts, topics, and even different content worlds. For example, concepts, topics, models, and theories that arise in a debate planned in a course on informal education may align with the content and concepts in a course for youth at-risk. We, as lecturers, must encourage our students to think laterally about their academic areas of study. The reflection and critical analysis of the debate also invite the students to reconsider their course curriculum.

\subsubsection{The Technological Dimension}

In the digital era, technology is an integral part of the students' teaching and learning experience. Technological tools are highly important in intensifying learning and assessment as they facilitate the use of various presentations of knowledge.

In the example presented here, the technological dimension is reflected in the many options that can be applied during a Zoom debate session; i.e., using Padlet, a collaborative board where students can write their ideas and arguments during the debate, students can organize the discussion orally. Another option is to conduct a poll or a survey in the classroom using Kahoot for a specific question for which we want to see the segmentation of students' responses. Other options include creating an animation using Animate, for the purpose of visually and interactively expressing and demonstrating an argument, an idea, a model, or a concept learned in the course.

As we have explained in this article, the basis of the model is evaluation, so it is important that each dimension is also reflected in the evaluation process itself. Each of these dimensions is reflected in formative assessment. The evaluation of the multiculturalism dimension is based on evaluating the student according to the extent to which he/she represents the voices of all students in the course and debate, and it gives interpretation and meaning to the contribution of students' culture-based attitudes and interpretations. Regarding the curriculum dimension, an important aspect in the students' evaluation is the process and rationale for their selection of a debate topic. In this process, the students review and critically examine all the content learned in the course and rationally select the most relevant topic for the debate. Finally, the choice of combining technological tools and their reasoning is also part of the evaluation process, in which the students explain why a particular tool was chosen and not another and how this tool contributed to the improvement of the debate.

\section{Summary}

In this article we provided a novel model for evaluation in higher education. Until Covid-19, the state-of-the-art in CRAE had been to try to make sure that the tools that educators use for evaluative purposes were appropriate in inclusive multicultural settings (Banks \& Banks 2010; Harry \& Klinger 2007; Vavrus, 2008). Covid-19 has dropped a weighty fourth variable into the CRAE mix: technological literacy and skills. Students today have access to fast, available, and accessible information, and their ability to consume information is constantly evolving. Our ability to weave global and virtual social connections has been greatly enhanced. Is academia able to keep up with such rapid changes? Can it adjust its teaching, learning, and evaluation methods to the students' world, in keeping with these rapid technological changes?

Whereas educators had been used to thinking about technology as being helpful for TLP and curricula, technology has not typically been included in CRAE. Due to the fact that Covid-19 has required all academic settings to utilize online learning, CRAE must pay careful attention to how technology is being used and what exactly is being achieved through its use. We introduced a CRAE for the $21^{\text {st }}$ century; i.e., culturally relevant evaluation that pays attention to technology as well as to pedagogy and curriculum. We know that evaluation affects TLP and curriculum (Levy-Vered \& Nasser-Abu Alhija, 2015), and in light of Covid-19 and the widespread use of online learning, meaningful evaluation today must include cultural relevance as well as the use of technology. After all, meaningful 
evaluation is not only about assessments and measurements but aims at getting a holistic view of the person we want to evaluate. Such a holistic view of the person must include their culture, gender, personality, learning style, technological abilities, etc. In this article, we presented our model and discussed its theoretical and practical implications for enhancing educational evaluation and assessment in higher education suitable for the multicultural era of the $21^{\text {st }}$ century.

\section{Compliance with Ethical Standards}

Conflict of interest: All five authors declare that they have no conflict of interest.

Ethical approval: This article does not contain any studies with human participants or animals performed by any of the authors.

Funding: Funding information is not applicable / No funding was received.

\section{References}

Achtenhagen, F. (2012). The curriculum-instruction-assessment triad. Empirical research in vocational education and training, 4(1), 5-25. https://doi.org/10.1007/BF03546504

Akyol, Z., Arbaugh, B., Cleveland-Innes, M., Garrison, R., Ice, P., Richardson, J., \& Swan, K. (2009). A response to the review of the Community of Inquiry Framework. Journal of Distance Education, 23(2), 123-136. Retrieved from https://files.eric.ed.gov/fulltext/EJ851908.pdf

Alemán, S. M. (2014). Locating whiteness in journalism pedagogy. Critical Studies in Media Communication, 31(1), 72-88. https://doi.org/10.1080/15295036.2013.808355

Alexander, R. (2004). Still no pedagogy? Principle, pragmatism and compliance in primary education. Cambridge Journal of Education, 34(1), 7-33. https://doi.org/10.1080/0305764042000183106

Alexander, R. (2018). Developing dialogic teaching: Genesis, process, trial. Research Papers in Education, 33(5), 561-598. https://doi.org/10.1080/02671522.2018.1481140

$\mathrm{Au}, \mathrm{W}$. (2010). Unequal by design: High-stakes testing and the standardization of inequality. New York: Routledge . https://doi.org/10.4324/9780203892046

Banks, J. A., \& Banks, C. A. M. (Eds.). (2019). Multicultural education: Issues and perspectives. Hoboken, NJ: John Wiley \& Sons.

Bar Shalom, Y., Grebelsky-Lichtman, T., \& Alayan, F. (2018). Intercultural encounters as a "Mind Body" experience: A case study in Jerusalem. Intercultural Education, 29(1), 139-147. https://doi.org/10.1080/14675986.2017.1405536

Bernacchio, C., \& Mullen, M. (2007). Universal design for learning. Psychiatric Rehabilitation Journal, 31(2), 167-169. https://doi.org/10.2975/31.2.2007.167.169

Birenbaum, M. (1997). Alternatives in achievement assessment. Tel Aviv University: Ramot. [Hebrew]

Birenbaum, M., \& Dochy, F. (Eds.). (2012). Alternatives in assessment of achievements, learning processes and prior knowledge (Vol. 42). New York: Springer Science \& Business Media.

Bjorklund-Young, A., \& Stratte Plasman, J. (2020). Reducing the achievement gap: Middle grades mathematics performance and improvement. Research in Middle Level Education, 43(10), 25-45. https://doi.org/10.1080/19404476.2020.1836467

Black, R. D., Weinberg, L. A., \& Brodwin, M. G. (2015). Universal design for learning and instruction: Perspectives of students with disabilities in higher education. Exceptionality Education International, 25(2), 1-16. https://doi.org/10.5206/eei.v25i2.7723

Black, P., \& Wiliam, D. (2018). Classroom assessment and pedagogy. Assessment in education: Principles, policy \& practice, 25(6), 551-575. https://doi.org/10.1080/0969594X.2018.1441807

Bransford, J. D., Brown, A. L., \& Cocking, R. R. (Eds.) (2000). How People Learn. Washington, DC: National Academy Press.

Butler, R., \& Orion, R. (1990). When pupils do not understand the determinants of their success and failure in school: Relations between internal, teacher and unknown perceptions of control and school achievement. British Journal of Educational Psychology, 60(1), 63-75. https://doi.org/10.1111/j.2044-8279.1990.tb00922.x 
Cantwell, B. (2019). Are international students cash cows? Examining the relationship between new international undergraduate enrollments and institutional revenue at public colleges and universities in the US. Journal of International Students, 5(4), 512-525. https://doi.org/10.32674/jis.v5i4.412

Case, J. M. (2013). Researching student learning in higher education: A social realist approach. New York: Routledge. https://doi.org/10.4324/9780203797402

Capp, M. J. (2017). The effectiveness of universal design for learning: A meta-analysis of literature between 2013 and 2016. International Journal of Inclusive Education, 21(8), $791-807$. https://doi.org/10.1080/13603116.2017.1325074

CAST. (2018). Universal Design for Learning Guidelines version 2.2. Retrieved from http://udlguidelines.cast.org

Chen, A. Y., Mashhadi, A., Ang, D., \& Harkrider, N. (1999). Cultural issues in the design of technology-enhanced learning systems. British Journal of Educational Technology, 30(3), 217-230. https://doi.org/10.1111/1467-8535.00111

De La Mare, D. M. (2014). Communicating for diversity: Using teacher discussion groups to transform multicultural education. The Social Studies, 105(3), 138-144. https://doi.org/10.1080/00377996.2013.859118

Dean, T., Lee-Post, A., \& Hapke, H. (2017). Universal design for learning in teaching large lecture classes. Journal of Marketing Education, 39(1), 5-16. https://doi.org/10.1177/0273475316662104

Ennouamani, S., Mahani, Z., \& Akharraz, L. (2020). A context-aware mobile learning system for adapting learning content and format of presentation: design, validation and evaluation. Education and Information Technologies, 25, 3919-3955. https://doi.org/10.1007/s10639-020-10149-9

Evmenova, A. (2018). Preparing teachers to use universal design for learning to support diverse learners. Journal of online learning research, 4(2), 147-171. Retrieved from https://files.eric.ed.gov/fulltext/EJ1184985.pdf

Ford, T. (2014). Becoming multicultural: Personal and social construction through critical teaching. New York: Routledge. https://doi.org/10.4324/9781315050485

Freire, P. (2018). Pedagogy of the oppressed: 50 th anniversary edition. New York: Bloomsbury.

Fuchs, L. S., Deno, S. L., \& Mirkin, P. K. (1984). The effects of frequent curriculum-based measurement and evaluation on pedagogy, student achievement, and student awareness of learning. American Educational Research Journal, 21(2), 449-460. https://doi.org/10.3102/00028312021002449

Gay, G. (2000). Culturally responsive teaching: theory, research, and practice. New York: Teachers College Press.

Ghosh, R., \& Galczynski, M. (2014). Redefining multicultural education: Inclusion and the right to be different (3 ${ }^{\text {rd }}$ ed.). Toronto: Canadian Scholars' Press, Inc.

Griful-Freixenet, J., Struyven, K., Verstichele, M., \& Andries, C. (2017). Higher education students with disabilities speaking out: Perceived barriers and opportunities of the universal design for learning framework. Disability \& Society, 32(10), 1627-1649. https://doi.org/10.1080/09687599.2017.1365695

Gulati, S. (2008). Technology-enhanced learning in developing nations: A review. The International Review of Research in Open and Distributed Learning, 9(1). https://doi.org/10.19173/irrodl.v9i1.477

Hambacher, E., \& Thompson, W. C. (2015). Breaking the mold: Thinking beyond deficits. Journal of Educational Controversy, 9(1). Retrieved from https://cedar.wwu.edu/jec/vol9/iss1/7/

Harry, B., \& Klinger, J. (2007). Improving instructions for students with learning needs. Educational Leadership,64(5), 16-21. Retrieved from https://www.ascd.org/el/improving-instruction-for-students-with-learning-needs

Heid, M. K. (1995). Algebra in a technological world. Curriculum and evaluation standards for School Mathematics Addenda Series, Grades 9-12. Reston, VA: National Council of Teachers of Mathematics.

Hendin, A. (2014). The community colleges model: Literature review. Jerusalem: Mayers-Joint-Brookdale. [Hebrew]

Kehrwald, B. (2010). Being online: Social presence as subjectivity in online learning. London Review of Education, 8(1), 39-50. https://doi.org/10.1080/14748460903557688

Kelley, B., Hosp, J. L., \& Howell, K. W. (2008). Curriculum-based evaluation and math: An overview. Assessment for Effective Intervention, 33(4), 250-256. https://doi.org/10.1177/1534508407313490 
Khalaila, R. (2015). The relationship between academic self-concept, intrinsic motivation, test anxiety, and academic achievement among nursing students: Mediating and moderating effects. Nurse Education Today, 35(3), 432-438. https://doi.org/10.1016/j.nedt.2014.11.001

Kirkwood, A., \& Price, L. (2014). Technology-enhanced learning and teaching in higher education: What is "enhanced" and how do we know? A critical literature review. Learning, Media and Technology, 39(1), 6-36. https://doi.org/10.1080/17439884.2013.770404

Ladson-Billings, G. (1995). Toward a theory of culturally relevant pedagogy .American Educational Research Journal, 32(3), 465-491. https://doi.org/10.3102/00028312032003465

Ladson-Billings, G. (2006). From the achievement gap to the education debt: Understanding achievement in US Schools. Educational Researcher, 35(7), 3-12. https://doi.org/10.3102/0013189X035007003

Legault, L., Green-Demers, I., \& Pelletier, L. (2006). Why do high school students lack motivation in the classroom? Toward an understanding of academic amotivation and the role of social support. Journal of educational psychology, 98(3), 567. https://doi.org/10.1037/0022-0663.98.3.567

Levy, H. (2003). A study of the attitudes of teachers, students and parents towards the evaluation of achievements in one elementary school. M.A. thesis in Humanities, Tel Aviv University. [Hebrew]

Levy-Vered, A., \& Nasser-Abu Alhija, F. (2015). Modelling beginning teachers' assessment literacy: The contribution of training, self-efficacy, and conceptions of assessment. Educational Research and Evaluation, 21(5-6), 378-406. https://doi.org/10.1080/13803611.2015.1117980

Liasidou, A. (2012). Inclusive education and critical pedagogy at the intersections of disability, race, gender and class. Journal for Critical Education Policy Studies (JCEPS), 10(1), 168-184. Retrieved from http://www.jceps.com/wp-content/uploads/PDFs/10-1-12.pdf

Luxton-Reilly, A. (2009). A systematic review of tools that support peer assessment. Computer Science Education, 19(4), 209-232. https://doi.org/10.1080/08993400903384844

Macedo, D. (2018). Introduction to the $50^{\text {th }}$ anniversary edition. In: P. Freire (Ed.), Pedagogy of the oppressed: $50^{\text {th }}$ anniversary edition (pp. 1-34). New York Bloomsbury.

Marginson, S., \& Considine, M. (2000). The enterprise university: Power, governance and reinvention in Australia. New York: Cambridge University Press.

McWhirter, N., \& Shealy, T. (2018). Pedagogy and evaluation of an envision case study module bridging sustainable engineering and behavioral science. Journal of Professional Issues in Engineering Education and Practice, 144(4). https://doi.org/10.1061/(ASCE)EI.1943-5541.0000384

Nevo, D. (1998). Dialogue evaluation: A possible contribution of evaluation to school improvement. Prospects, 28(1), 77-89. https://doi.org/10.1007/BF02737781

Nieto, S. (2010). Language, culture, and teaching: Critical perspectives. New York: Routledge.

Nieto, S. (2015). The light in their eyes: Creating multicultural learning communities. New York: Teachers College, Columbia University.

Patton, D. (2011). Evaluating the culturally relevant and responsive education professional development program at the elementary school level in the Los Angeles Unified School District. Learning Disabilities: A Contemporary Journal, 9(1), 71-107. Retrieved from https:/files.eric.ed.gov/fulltext/EJ925536.pdf

Paris, D., \& Alim, H. S. (2014). What are we seeking to sustain through culturally sustaining pedagogy? A loving $\begin{array}{llll}\text { critique } & \text { forward. Harvard Review, 84(1), 85-100. }\end{array}$ https://doi.org/10.17763/haer.84.1.9821873k2ht16m77

Pellegrino, J. W., Chudowsky, N., \& Glaser, R. (2001). Knowing what students know: The science and design of educational assessment. Washington, DC: National Academy Press.

Sanders, W. L., Wright, S. P., \& Horn, S. P. (1997). Teacher and classroom context effects on student achievement: Implications for teacher evaluation. Journal of personnel evaluation in education, 11(1), 57-67. https://doi.org/10.1023/A:1007999204543

Rhoads, R. A., \& Valadez, J. R. (2016). Democracy, multiculturalism, and the community college: A critical perspective. New York: Routledge. https://doi.org/10.4324/9781315050843 
Rose, D. H., Harbour, W. S., Johnston, C. S., Daley, S. G., \& Abarbanell, L. (2006). Universal design for learning in postsecondary education: Reflections on principles and their application. Journal of Postsecondary Education and Disability, 19(2), 135-151. Retrieved from https://files.eric.ed.gov/fulltext/EJ844630.pdf

Royce, A. S. (2007). The campus survey: Integrating pedagogy, scholarship, and evaluation. Teaching Sociology, 35(1), 48-61. https://doi.org/10.1177/0092055X0703500104

Saint-Hilaire, L. A. (2014). So, how do I teach them? Understanding multicultural education and culturally relevant pedagogy. Reflective Practice, 15(5), 592-602. https://doi.org/10.1080/14623943.2014.900026

Schneider, M., \& Preckel, F. (2017). Variables associated with achievement in higher education: A systematic review of meta-analyses. Psychological Bulletin, 143(6), 565-600. https://doi.org/10.1037/bul0000098

Sleeter, C. (2016). Ethnicity and the curriculum. In: D. Wyse., L, Hayward., \& J. Pandya (Eds.), The SAGE handbook of curriculum, pedagogy, and assessment (pp. 231-246). Thousand Oaks, CA: Sage Publications. https://doi.org/10.4135/9781473921405.n15

Sleeter, C., \& Carmona, J. F. (2017). Un-standardizing curriculum: Multicultural teaching in the standards-based classroom. New York: Teachers College, Columbia University.

Stecker, P. M., Fuchs, L. S., \& Fuchs, D. (2005). Using curriculum-based measurement to improve student achievement: Review of research. Psychology in the Schools, 42(8), 795-819. https://doi.org/10.1002/pits.20113

Taylor, J., \& Evans, D. (2005). Pulling together: keeping track of pedagogy, design and evaluation through the development of scenarios-a case study. Learning, Media and Technology, 30(2), 131-145. https://doi.org/10.1080/17439880500093588

Thomas, C. N., Van Garderen, D., Scheuermann, A., \& Lee, E. J. (2015). Applying a universal design for learning framework to mediate the language demands of mathematics. Reading \& Writing Quarterly, 31(3), 207-234. https://doi.org/10.1080/10573569.2015.1030988

Torres, M. N. (1996). Teachers' discursive practices: Co-construction of their group voices. Issues in Applied Linguistics, $\quad 7(2), \quad 251-278 . \quad$ Retrieved from https://escholarship.org/content/qt5x43318d/qt5x43318d_noSplash_d73cb318852f95359a628db68d3517b8.pdf $? \mathrm{t}=\lg 5 \operatorname{tn} 0$

Vavrus, M. (2008). Culturally responsive teaching. In T. L. Good (Ed.), 21st century education: A reference handbook (vol. 2), (pp. 49-57). Thousand Oaks, CA: Sage Publications. https://doi.org/10.4135/9781412964012.n56

Vonderwell, S., Liang, X., \& Alderman, K. (2007). Asynchronous discussions and assessment in online learning. Journal of Research on Technology in Education, 39(3), 309-328. https://doi.org/10.1080/15391523.2007.10782485

Vrasidas, C., \& McIsaac, M. S. (2000). Principles of pedagogy and evaluation for web-based learning. Educational Media International, 37(2), 105-111. https://doi.org/10.1080/095239800410405

Zeidner, M. (1993). Attitudes and perceptions of teachers and students toward giving grades and school assessment. Studies in Educational Management and Organization, 19, 47-70. [Hebrew]

\section{Copyrights}

Copyright for this article is retained by the author(s), with first publication rights granted to the journal.

This is an open-access article distributed under the terms and conditions of the Creative Commons Attribution license (http://creativecommons.org/licenses/by/4.0/). 